\title{
Postoperative atrial fibrillation: Still in search of truth or a neglected complication?
}

\author{
Vito D. Bruno, MD, PhD, and Raimondo Ascione, FRCS, MD, ChM \\ From the Bristol Heart Institute, School of Clinical Sciences, University of Bristol, Bristol, United Kingdom. \\ Disclosures: Authors have nothing to disclose with regard to commercial support. \\ Received for publication Sept 5, 2017; accepted for publication Sept 8, 2017; available ahead of print Oct 18, \\ 2017. \\ Address for reprints: Vito D. Bruno, $\mathrm{MD}, \mathrm{PhD}$, Bristol Heart Institute, Faculty of Health Science, University of \\ Bristol, Marlborough St, BS2 8HW, Bristol, United Kingdom (E-mail: Vito.D.Bruno@bristol.ac.uk). \\ J Thorac Cardiovasc Surg 2018;155:236-7 \\ 0022-5223/\$36.00 \\ Copyright (c) 2017 by The American Association for Thoracic Surgery \\ https://doi.org/10.1016/j.jtcvs.2017.09.035
}

Despite being the most common complication after cardiac surgery, ${ }^{1}$ affecting up to $50 \%$ of treated patients, ${ }^{2}$ postoperative atrial fibrillation (PoAF) still remains a challenge to face. Although PoAF is regarded generally as a transient and tolerated postoperative complication, it is worth noting that it can trigger life-threatening complications such as stroke, cardiogenic shock, and ventricular arrhythmias, particularly in the ever-increasing elderly population and those presenting with impaired left ventricular function, leading to prolonged length of hospital stay and increased costs. The pathophysiology of PoAF remains uncertain, whereas the cause is multifactorial. Factors associated with PoAF include the nonphysiologic nature of the cardiopulmonary bypass and cardioplegic arrest, cardiac manipulations, inflammatory response, myocardial ischemia-reperfusion injury, pharmacologic triggers, and others.

The article by Akintoye and colleagues, ${ }^{4}$ based on a subanalysis of the patients recruited in the Omega-3 Fatty Acids for Prevention of Post-Operative Atrial Fibrillation (OPERA) trial, expands on this knowledge. The work confirms that the type of surgery and use of cardiopulmonary bypass predict PoAF, prolonging hospital stay, as also reported by our group and others. ${ }^{5,6}$ In addition, it suggests that PoAF may be associated with increased 1-year mortality, which is of concern.

The work provides evidence of a direct correlation of PoAF with the extent of the surgery. The use of interaction terms has been of value, allowing to discern the role of different contributing components within a given predictor of PoAF; for example, the authors found that the risk of developing PoAF was significantly lower in off-pump surgery, and within this group of patients was affected to a less extent by male gender and younger age.

The finding of an association between PoAF and 1-year mortality is a concern, even if no data are provided by the authors on the cause of late death and rate of recurrence of atrial fibrillation after hospital discharge, as well as duration of anticoagulation and antiarrhythmic drugs

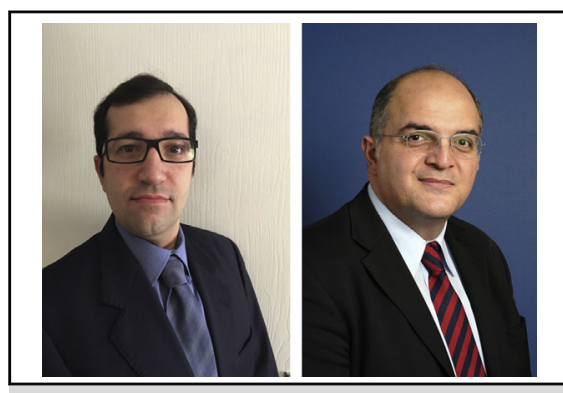

Vito D. Bruno, MD, PhD, and Raimondo Ascione, FRCS, MD, ChM

\section{Central Message}

Can a better baseline risk profiling prevent POAF? And can a more appropriate anticoagulation after discharge reduce the incidence of late complications?

See Article page 242 used. Indeed, postdischarge anticoagulation management in patients with PoAF presenting in sinus rhythm is a grey area not firmly covered by current guidelines, despite previous evidence suggesting a 3-fold higher rate of stroke in patients with PoAF. ${ }^{3}$ This is of particular concern when considering that a recently published study suggests that the Society of Thoracic Surgery Database misses approximately 10,000 patients with PoAF yearly. ${ }^{7}$ This might highlight a potential neglect of this complication that could worsen the related long-term consequences and have an impact on the implementation of preventive measures.

Of note, the study has some limitations, mainly related to its nonrandomized nature, to the lack of distinction between short and sustained episodes of PoAF, and to the presence of multicollinearity in the predictive model. Overall, however, we think that the study reinforces the need to continue searching for the truth behind the occurrence of PoAF to avoid potential neglect.

In an ideal world, a possible multifaceted approach to face this challenge might include the following: (1) better baseline risk profiling and risk scoring to predict PoAF; (2) intraoperative measures to control or avoid the known predisposing factors in the presence of high PoAF scores; and (3) consider a more effective early and midterm anticoagulation management for patients with PoAF, possibly including the extension of direct factor $\mathrm{Xa}$ inhibitors to this patient category as part of a dedicated trial. 


\section{References}

1. Bessissow A, Khan J, Devereaux PJ, Alvarez-Garcia J, Alonso-Coello P. Postoperative atrial fibrillation in non-cardiac and cardiac surgery: an overview. J Thromb Haemost. 2015;13(S1):S304-12.

2. Melby SJ, George JF, Picone DJ, Wallace JP, Davies JE, George DJ, et al. A time-related parametric risk factor analysis for postoperative atrial fibrillation after heart surgery. J Thorac Cardiovasc Surg. 2015; 149:886-92.

3. Mathew JP. Atrial fibrillation following coronary artery bypass graft surgery. JAMA. 1996;276:300.

4. Akintoye E, Sellke F, Marchioli R, Tavazzi L, Mozaffarian D. Factors associated with postoperative atrial fibrillation and other adverse

events after cardiac surgery. J Thorac Cardiovasc Surg. 2018;155: 242-51.e10.

5. Echahidi N, Pibarot P, O'Hara G, Mathieu P. Mechanisms, prevention, and treatment of atrial fibrillation after cardiac surgery. J Am Coll Cardiol. 2008;51: 793-801.

6. Ascione R, Caputo M, Calori G, Lloyd CT, Underwood MJ, Angelini GD Predictors of atrial fibrillation after conventional and beating heart coronary surgery. A prospective, randomized study. Circulation. 2000;102:1530-5.

7. Filardo G, Pollock BD, da Graca B, Phan TK, Sass DM, Ailawadi G, et al Underestimation of the incidence of new-onset post-coronary artery bypass grafting atrial fibrillation and its impact on 30-day mortality. J Thorac Cardiovasc Surg. 2017;154:1260-6. 